eISSN 2444-7986

DOI: https://doi.org/10.14201/orl.17173

Artículo original

\title{
REVISIÓN SOBRE LA IMPORTANCIA CLÍNICA DEL NISTAGMO ESPONTÁNEO Y DE LA PRUEBA DE AGITACIÓN CEFÁLICA
}

\section{A review of clinical significance of spontaneous nystagmus and head shaking test}

\author{
Sara FERNANDEZ-CASCÓN'; Raquel FERNANDEZ-MORÁIS'; Rafael ÁLVAREZ-OTERO² \\ ${ }^{1}$ SACYL. Hospital Universitario Río Hortega de Valladolid. Servicio de Otorrinolaringología. Valladolid. España. ${ }^{2} S A C Y L$. \\ Complejo Asistencial Universitario de Palencia. Servicio de Otorrinolaringología. Palencia. España
}

Correspondencia: dralvarezorl@gmail.com

Fecha de recepción: 1 de noviembre de 2017

Fecha de aceptación: 28 de noviembre de 2017

Fecha de publicación: 30 de noviembre de 2017

Fecha de publicación del fascículo: 1 de junio de 2018

Conflicto de intereses: Los autores declaran no tener conflictos de intereses

Imágenes: Los autores declaran haber obtenido las imágenes con el permiso de los pacientes

Política de derechos y autoarchivo: se permite el autoarchivo de la versión post-print (SHERPA/RoMEO)

Licencia CC BY-NC-ND. Licencia Creative Commons Atribución-NoComercial-SinDerivar 4.0 Internacional

Universidad de Salamanca. Su comercialización está sujeta al permiso del editor

RESUMEN

Introducción y objetivo: La exploración clínica otoneurológica suele iniciarse por la exploración oculomotora. Dicha exploración nos permite evaluar los signos estáticos, como el nistagmo espontáneo (NE), y los signos dinámicos, como el nistagmo post agitación cefálica, el nistagmo por vibración mastoidea o la maniobra de impulso oculocefálico. El objetivo de esta revisión consiste en exponer las bases fisiopatológicas del nistagmo espontáneo y la prueba de agitación cefálica, así como su utilidad clínica. Método: Se trata de una revisión narrativa donde seleccionamos la bibliografía que consideramos más relevante para dicho objetivo. Resultado: Describimos el nistagmo como el movimiento involuntario y rítmico de los ojos que puede aparecer de forma espontánea o provocado por diferentes estímulos. La exploración del nistagmo espontáneo en las 5 posiciones de la mirada, al igual que su caracterización, es la herramienta fundamental en la valoración inicial de un paciente mareado, seguida de la realización de diferentes maniobras que puedan ponerlo de manifiesto o modificarlo. Conclusión: La aparición de un nistagmo espontáneo de características periféricas en el contexto de una vestibulopatía unilateral aguda junto con la progresión de los signos dinámicos, son indicadores de la situación clínica del paciente y el grado de compensación vestibular.

PALABRAS CLAVE nistagmo espontáneo; test de agitación cefálica; vestibulopatía aguda 

tor examination. This exploration allows us to evaluate static signs, such as spontaneous nystagmus, and dynamic signs such as post head-shaking nystagmus, mastoid vibration nystagmus or oculocephalic impulse test. The objective of this review will be to expose the physiopathological bases of spontaneous nystagmus and the head-shaking test as well as its clinical utility. Method: It is a narrative review where we select the bibliography that we consider most relevant for this objective. Results: We describe nystagmus as the involuntary and rhythmic movement of the eyes which appears spontaneously or provoked by different stimuli. The exploration of spontaneous nystagmus in the 5 positions of the look, as well as its characteristic, is the fundamental tool in the initial assessment of a dizzy patient, followed by performing different maneuvers that can make it to manifest or to modify. Conclusion: The appearance of a spontaneous nystagmus of peripheral characteristics in the context of an acute unilateral vestibulopathy together with the progression of the dynamic signs, are indicators of the clinical situation of the patient and the degree of vestibular compensation.

\section{INTRODUCCIÓN}

La exploración oculomotora, es el primer paso en toda valoración otoneurológica, la cual nos permite evaluar tanto signos estáticos como el nistagmo espontáneo y signos dinámicos como el nistagmo de agitación cefálica (NAC), el nistagmo inducido por vibración mastoidea o la maniobra de impulso oculocefálico.

El nistagmo se define como las oscilaciones rítmicas e involuntarias de los ojos. La aparición de un nistagmo espontáneo indica la existencia de una correspondencia inadecuada (asimetría) en la actividad basal de descarga de ambos núcleos vestibulares, de forma que se produce una deriva ocular hacia el lado hipofuncionante interrumpida por una sacudida de refijación contraria.

El sentido al que se dirige la fase rápida, más fácil de apreciar, indica el sentido lineal del nistagmo que puede ser derecho/izquierdo o superior/inferior. Además, el giro del globo ocular sobre su eje axial nos revela si existe un componente torsional o rotatorio. Este último puede girar en sentido horario o antihorario y combinarse con un componente lineal (nistagmo mixto).

En ausencia de nistagmo espontáneo podemos estar ante un sistema vestibular normofuncionante o compensado. Cuando aparece, tendremos que considerarlo en el diagnóstico diferencial de una vestibulopatía unilateral aguda, ya sea de origen central o periférica. $\mathrm{Si}$ no está presente, podremos recurrir a diferentes maniobras de exploración clínica para evidenciar un desequilibrio vestibular latente. Una de estas técnicas sería la prueba de agitación cefálica $[1,2]$.

El nistagmo que aparece tras agitar la cabeza es un fenómeno descrito por Bárány en 1907 [3] Vogel describió la primera técnica reglada en 1929 y ya entonces se explicó su práctica tras la exploración del nistagmo espontáneo $[4,5]$. Posteriormente la prueba fue evolucionando mediante la aplicación de gafas de Frenzel o videonistagmografía para eliminar la fijación visual y aumentando el número de sacudidas cefálicas o de planos explorados. La prueba moderna se realiza según la técnica descrita por Kamei et al. en 1964 [6] que luego describiremos y cuya interpretación depende, de la presencia o no de nistagmo espontáneo. Cuando realizamos una maniobra de agitación cefálica, el reflejo vestíbulo-ocular intenta mantener estable la posición del ojo, para ello utiliza movimientos compensadores que se traducen en una respuesta en forma de nistagmo. Cuando paramos bruscamente la maniobra, esta condición se mantiene durante un corto periodo de tiempo debido a que se carga el sistema central de almacenamiento de velocidad, cuya función permite que la actividad vestibular persista a pesar de que el estímulo haya cesado. Por lo tanto, al anularse los procesos adaptativos a la condición patológica, se generan sacadas hacia el lado contrario del lado deficitario [7, 8].

\section{EXPLORACIÓN \\ EXPLORACIÓN DEL NISTAGMO ESPONTÁNEO}

La búsqueda y la exploración del nistagmo espontáneo se basa en reconocer su sentido y determinar la influencia que tienen la fijación visual, la desviación ocular y los cambios posicionales. Por lo tanto, deberemos explorar el nistagmo espontáneo con y sin fijación visual. Para valorar el nistagmo espontáneo con fijación visual nos situamos con el paciente sentado en frente nuestro y le pedimos que mire hacia un punto fijo situado a unos $50 \mathrm{~cm}$ de distancia (nuestro dedo o la punta de un bolígrafo); entonces vamos dirigiendo su mirada al 
frente, a la derecha, a la izquierda, arriba y abajo. Conviene permanecer unos segundos en cada dirección por si el nistagmo apareciese con cierta latencia.

En cada cambio de dirección, basta con desviar los ojos hasta $30^{\circ}$ desde la mirada al frente. Si se excede este ángulo de desviación, puede aparecer el nistagmo de mirada extrema o de la punta, el cual no se considera patológico.

Para suprimir la fijación ocular podemos emplear varios métodos, pero principalmente y por su accesibilidad, utilizaremos las gafas de Frenzel en una habitación a oscuras. Volveremos a explorar el nistagmo espontáneo sin fijación visual en las cinco posiciones de la mirada, dirigiendo al paciente para que no desvíe los ojos más de $30^{\circ}$.

La oftalmoscopia es el método que impide la fijación visual casi al 100\%, pero tiene el inconveniente que la valoración se hace en el sentido opuesto al polo anterior del ojo ya que visualizamos el desplazamiento retiniano o del polo posterior.

La videoculografía permite estudiar el movimiento ocular en la oscuridad mediante una o dos cámaras infrarrojas, ampliado su imagen en una pantalla y al mismo tiempo generar un registro gráfico de los movimientos en el eje horizontal y en el vertical.

En la neuritis vestibular, por ejemplo, durante la fase aguda el paciente presenta un nistagmo espontáneo horizontal, en posición primaria de la mirada, que reúne todas las características del patrón periférico. Tras 3-5 días, gracias a la rápida compensación del tono basal de los núcleos vestibulares, la fijación visual suprime dicho nistagmo. Podremos seguir observándolo bajo unas gafas de Frenzel durante dos o tres semanas cuando el paciente dirige la mirada hacia el lado de la fase rápida $[9,10]$.

\section{REALIZACIÓN DE LA PRUEBA DE AGITACIÓN CEFÁLICA}

Tras explicar al paciente en qué consiste la prueba, lo más importante es preguntarle por sus antecedentes de patología vascular o vertebral en la columna cervical. Para la mayor parte es una prueba bien tolerada.

Con la luz de la habitación apagada o en penumbra, se colocan al paciente unas gafas de Frenzel o, si disponemos de ellas, unas gafas de videoculografía. Conviene vigilar la aparición de movimientos espontáneos de los ojos durante unos 10 segundos antes de iniciar la agitación. Sujetamos firmemente la cabeza inclinada $30^{\circ}$ en anteflexión, y la hacemos girar enérgicamente de derecha a izquierda con una frecuencia de 2 a 3 veces por segundo hasta completar entre 20 y 30 ciclos. Tras detener la cabeza bruscamente, pedimos al paciente que abra los ojos. La amplitud aproximada del giro en el plano horizontal es entre 30 y $45^{\circ}$ a cada lado (Figura 1). Esta prueba también se puede practicar en el plano sagital y en el frontal, aunque su realización e interpretación es más difícil. No es conveniente realizar más de 30 ciclos [8].

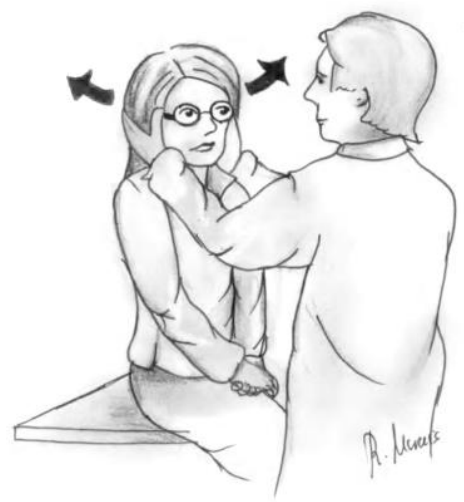

Figura 1: Exploración del nistagmo de agitación cefálica. (Imágenes propias)

\section{INTERPRETACIÓN DE LOS RESULTADOS DE LA EXPLORACIÓN \\ NISTAGMO ESPONTÁNEO}

La exploración del nistagmo espontáneo debe ser sistemática y atendiendo a las diferentes características de este:

- Observaremos si el movimiento ocular es conjugado, es decir, si ambos ojos se mueven simultáneamente, con idéntica dirección, con la misma intensidad y durante el mismo tiempo. Si alguna de dichas condiciones no está presente, catalogaremos el nistagmo como disociado.

- Morfología del nistagmo, que puede ser:

- En resorte o en sacudidas cuando distinguimos una fase lenta y otra rápida de dirección opuesta.

- Pendular u ondulatorio cuando observamos un movimiento ocular de un lado a otro de igual velocidad en ambos sentidos.

- Irregular, cuando no cumple ninguna de las características anteriores. 
- Dirección del nistagmo: Horizontal, vertical, rotatorio o torsional y mixto. La dirección del nistagmo viene determinada por la fase rápida del mismo.

- La intensidad del nistagmo se cuantifica en grados según la ley de Alexander: el nistagmo aparece o aumenta su frecuencia al desplazar el ojo en la dirección de la fase rápida del mismo, lo cual sugiere patología periférica:

- Grado 1: Aparece sólo al mirar hacia el lado donde bate la fase rápida.

- Grado 2: Hacia la fase rápida + mirada al frente.

- Grado 3: Hacia la fase rápida + mirada al frente + hacia la fase lenta.

- Ritmo y amplitud: El ritmo de las oscilaciones puede ser bajo (< una por segundo), medio (una o dos por segundo), alto ( $>$ de dos por segundo). En cuanto a la amplitud puede ser pequeña $(<1 \mathrm{~mm})$, media (1 a $3 \mathrm{~mm}$ ) o grande (>3mm). Se denomina nistagmo isócrono, a aquel que presenta intervalos homogéneos y amplitud constante en sus sacudidas.

A continuación, la exploración del nistagmo debe realizarse impidiendo la fijación de la mirada del paciente. Para ello se utilizan unas gafas especiales con unas 20 dioptrías, las llamadas gafas de Frenzel. Esta sencilla prueba nos puede orientar sobre si nos encontramos ante un nistagmo central o uno periférico.

Cuando anulamos la fijación de la mirada pueden darse las siguientes situaciones:

- Aparición de un nistagmo espontáneo o aumento del ya existente: es el caso propio de un nistagmo de origen periférico.

- Disminución de la intensidad del nistagmo espontáneo o su desaparición: debe hacernos sospechar centralidad en su topodiagnóstico, denominándose entonces nistagmo de fijación. [1, 2, 7, 9].

Clásicamente, el nistagmo espontáneo se divide en central y periférico, tomando cada uno de ellos unas características que se señalan en la tabla 1. En el patrón periférico, el nistagmo es casi siempre de origen vestibular periférico y está constituido por dos fases, la rápida y la lenta, que lo diferencian del ondulatorio o pendular, en los que el nistagmo tiene la misma velocidad en ambas direcciones.
Los casos de origen vestibular periférico se acompañan de un nistagmo espontáneo que suele ser horizontal, rotatorio u horizontorotatorio, en tanto que en los de etiología central la dirección puede ser vertical $u$ oblicua. Además, la oscilación ocular es conjugada, tratándose de un nistagmo asociado. En contraposición, en el nistagmo disociado los ojos no se mueven en la misma dirección, con igual intensidad y al mismo tiempo; esta disociación sugiere una alteración central o patología del globo ocular.

El diagnóstico de una vestibulopatía aguda periférica parece sencillo con todo lo expuesto hasta ahora, sin embargo, en el diagnóstico diferencial del nistagmo espontáneo de patrón central se describen numerosos tipos de nistagmo que nos pueden orientar sobre qué estructura cerebelosa o troncoencefálica puede estar comprometida. Los más comunes son los nistagmos verticales, que habitualmente se originan por una disfunción del cerebelo [11].

Tabla 1: Caracterización del Nistagmo espontáneo.

\begin{tabular}{|l|l|}
\hline Patrón Periférico & Patrón central \\
\hline $\begin{array}{l}\text { Unidireccional: } \\
\text { horizontorrrotatorio }\end{array}$ & $\begin{array}{l}\text { Unidireccional } \\
\text { multidireccional: cualquier } \\
\text { dirección }\end{array}$ \\
\hline $\begin{array}{l}\text { Fase lenta hacia lado } \\
\text { hipovalente. En resorte }\end{array}$ & Pendular o en resorte \\
\hline $\begin{array}{l}\text { Se intensifica al mirar hacia } \\
\text { el sentido de la fase rápida } \\
\text { (Ley de Alexander) }\end{array}$ & $\begin{array}{l}\text { No sigue la ley de } \\
\text { Alexander }\end{array}$ \\
\hline $\begin{array}{l}\text { Se reduce por la fijación } \\
\text { visual } \\
\text { Se incrementa al suprimir la } \\
\text { fijación visual }\end{array}$ & $\begin{array}{l}\text { Sostenido: no se modifica } \\
\text { o se reduce por la fijación }\end{array}$ \\
\hline $\begin{array}{l}\text { Movimientos } \\
\text { conjugados }\end{array}$ & $\begin{array}{l}\text { Movimientos conjugados o } \\
\text { disociados }\end{array}$ \\
\hline
\end{tabular}

ALGUNOS NISTAGMOS DE ORIGEN CENTRAL:

- Nistagmo de rebote: el cual podemos explorar deteniendo la mirada del paciente cada vez que pasemos por la posición primaria central. Primero mantenemos unos 10 segundos la mirada hacia un lado y volvemos rápidamente hacía el centro. Batirá 3-5 veces en sentido contrario al que se desplazaban los ojos justo antes de detenerse. Es frecuente en pacientes con enfermedad cerebelosa parenquimatosa, aunque puede aparecer en individuos normales si inhibimos la fijación de la mirada. 
- Nistagmo voluntario: puede ser un intento consciente de aparentar un nistagmo espontáneo, se caracteriza por su oscilación horizontal de baja amplitud, extremadamente rápida entre $8-23 \mathrm{~Hz}$ y una duración máxima de 30 segundos.

- Nistagmo evocado por la mirada o direccional: El integrador neural es incapaz de mantener la posición excéntrica del ojo, es decir, cuando el paciente coloca los ojos en mirada lateral. Es de frecuencia lenta o de gran amplitud, velocidad decreciente y también aparece en individuos normales en la oscuridad. Cambia el sentido del nistagmo con la dirección de la mirada (bate hacia la derecha al mirar a la derecha y a la izquierda al mirar a la izquierda). Hay que descartar el nistagmo fisiológico de mirada extrema, que se produce cuando se lleva la mirada del paciente más de $40^{\circ}$ desde la posición primaria. Este Nistagmo de dirección cambiante, que se explora al llevar a cabo el protocolo HINTS (head impulse, nystagmus, test of skew), señala una alteración en las estructuras cerebelosas y del tronco del encéfalo. Este tipo de nistagmo resulta muy sugestivo de patología central [12]. En un paciente con un NE de patrón periférico, el sentido del nistagmo se mantiene, aunque cambiemos la dirección de la mirada.

- Nistagmo pendular: Descrito como un movimiento involuntario de los ojos, bidireccional, compuesto por fases lentas de igual velocidad sin sacadas correctoras. Puede ser congénito, que se inicia con el nacimiento y persiste a lo largo de la vida; y adquirido, asociado a lesiones a nivel troncoencefálico 0 núcleos profundos cerebelosos.

- Nistagmo vertical: Su patogenia implica a una gran cantidad de sistemas neuronales. En cualquier caso, tanto el nistagmo hacia arriba como hacia abajo, se exacerba con los cambios de posición de la cabeza. Ello sugiere un desequilibrio central de la señal otolítica. Hacia arriba o upbeat nystagmus (figura 2.C): Se asocia a tumores troncoencefálicos, infarto, hematoma, cavernoma, esclerosis múltiple, encefalitis, absceso, degeneración alcohólica (encefalopatía de Wernicke) e intoxicación farmacológica. El nistagmo provocado que se asocia a un vértigo posicional paroxístico benigno (VPPB) del canal semicircular posterior lleva asociado un componente torsional. Hacia abajo o downbeat nystagmus (figura 2.D): Se puede asociar a múltiples lesiones, principalmente de la fosa posterior y de la unión craneocervical. Un nistagmo provocado vertical inferior también puede apreciarse en un VPPB del canal semicircular superior, distinguiéndose del tipo central en que cumple las características de un vértigo posicional.

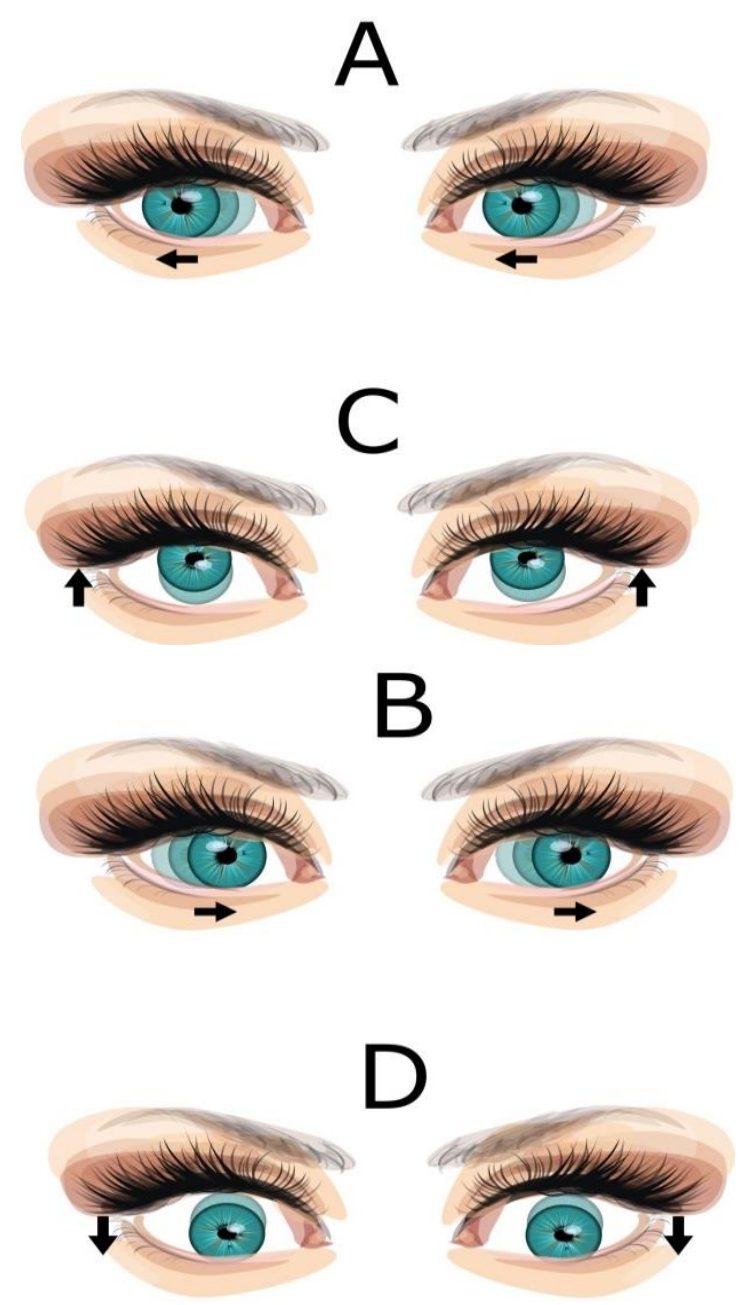

Figura 2: A: Fase primaria con nistagmo parético hacia lado sano (derecho) B: Fase secundaria con nistagmo opuesto de menos intensidad. C: Upbeat nystagmus. D: Downbeat nystagmus. (Imágenes propias).

- Nistagmo alternante periódico: Invierte su dirección cada dos minutos, no necesariamente en el plano horizontal. Podemos encontrarlo en la malformación 
de Arnold-Chiari, la esclerosis múltiple, la degeneración cerebelosa, tumor, absceso, quiste, y otras masas cerebelosas, ataxia teleangiectasica, infarto troncoencefálico, medicación anticonvulsivante, infección cerebelosa, traumatismos, pérdida visual (hemorragia vítrea, cataratas), y nistagmo congénito.

- Hay otros nistagmos espontáneos como el nistagmo congénito, el latente (que aparece con visión monocular), el del invidente o nistagmo de Bruns (que sería otra variante de nistagmo direccional).

NISTAGMO DE AGITACIÓN CEFÁLICA (NAC)

La prueba de agitación cefálica pone en evidencia una asimetría funcional de las aferencias vestibulares. La presencia de 5 o más nistagmos horizontales, y con una velocidad de fase lenta mayor de 2-3 grados/segundo, orienta a un patrón periférico. El sentido de la fase lenta indicaría el laberinto posterior hipovalente, es decir, los nistagmos baten hacia el lado predominante. La aparición de 2 o 3 sacudidas nistágmicas puede ser normal. En los pacientes con nistagmo espontáneo, tras la agitación, se observaría un claro incremento de la frecuencia nistágmica hacia el lado sano. En el patrón central se obtienen nistagmos disarmónicos, muchas veces verticales, que no se correlacionan ni con la intensidad de las maniobras ni con el lado lesionado [13] (Tabla 2).

La clasificación del NAC se hace de acuerdo con su:

- Morfología: Monofásico, cuando el nistagmo se mantiene en el mismo sentido, o bifásico, si presenta una fase secundaria en la que el nistagmo bate en sentido inverso al de la primera fase. En el NAC bifásico hablaremos de fase primaria a la que aparece primero, y fase secundaria o inversa, a la que se aprecia después. Si la fase primaria fuera muy corta, podría dificultar la interpretación de la prueba.

- Fase rápida: Parético, cuando la fase primaria bate hacia el lado sano (figura 2.A), e invertido, cuando bate hacia el lado afecto (figura 2.B). El motivo por el que aparece este nistagmo invertido se explica por el mismo mecanismo que posibilita la aparición de un nistagmo de recuperación. Es decir, la recuperación de la función vestibular cuando los mecanismos de compensación ya se han puesto en marcha, provoca un desequilibrio hacia el lado inicialmente lesionado.

- Dirección del nistagmo: la mayoría son horizontales, pero en algunas ocasiones aparece un nistagmo vertical de gran intensidad con la agitación en el plano horizontal. En estos casos se habla de nistagmo pervertido o nistagmo cruzado (cross-coupled nystagmus) y se considera que indica la existencia de una lesión central. Denominamos por tanto nistagmo cruzado, a aquel que no se correlaciona con el plano de agitación estimulado [6].

Tabla 2: Caracterización del Nistagmo post-agitación cefálica.

\begin{tabular}{|c|c|c|}
\hline & Patrón periférico & Patrón central \\
\hline $\begin{array}{l}\text { Fase } \\
\text { Primaria }\end{array}$ & $\begin{array}{l}\text { Nistagmo parético } \\
\text { (que bate hacia el } \\
\text { lado sano) }\end{array}$ & $\begin{array}{l}\text { La dirección del } \\
\text { nistagmo no se } \\
\text { correlaciona con } \\
\text { la lesión. Es } \\
\text { típica } \\
\text { aparición de un } \\
\text { nistagmo } \\
\text { vertical tras } \\
\text { agitación. }\end{array}$ \\
\hline $\begin{array}{l}\text { Fase } \\
\text { Secundaria }\end{array}$ & $\begin{array}{l}\text { Constante y débil. } \\
\text { El nistagmo bate } \\
\text { hacia el lado } \\
\text { opuesto. }\end{array}$ & $\begin{array}{l}\text { Variable. Puede } \\
\text { ser tan intensa o } \\
\text { incluso más que } \\
\text { la primera fase. }\end{array}$ \\
\hline $\begin{array}{l}\text { Maniobra } \\
\text { horizontal }\end{array}$ & $\begin{array}{l}\text { Nistagmo vertical } \\
\text { cruzado muy leve } \\
\text { o inexistente }\end{array}$ & te \\
\hline $\begin{array}{l}\text { Maniobra } \\
\text { vertical }\end{array}$ & $\begin{array}{lr}\text { Puede } & \text { aparecer } \\
\text { un nistagmo } & \\
\text { horizontorrotatorio } \\
\text { hacia el lado } \\
\text { enfermo. }\end{array}$ & $\begin{array}{l}\text { nistagmo } \\
\text { cruzado intenso }\end{array}$ \\
\hline $\begin{array}{l}\text { Provocación } \\
\text { del nistagmo }\end{array}$ & $\begin{array}{l}\text { No aparece, a } \\
\text { menos que la } \\
\text { maniobra sea muy } \\
\text { vigorosa. }\end{array}$ & $\begin{array}{l}\text { Puede aparecer } \\
\text { tras } 1-2 \text { ciclos } \\
\text { con maniobra } \\
\text { leve. }\end{array}$ \\
\hline
\end{tabular}

En lesiones periféricas unilaterales, el movimiento de agitación de la cabeza genera una asimetría en la actividad neural entre el laberinto sano y el enfermo que nosotros podemos observar como un nistagmo hacia el lado sano [5]. Esta asimetría puede ir acumulándose a nivel central en el complejo neuronal que constituye el mecanismo de almacenamiento de velocidad (núcleo vestibular medial y núcleo prepósito del hipogloso) para liberarse al finalizar la maniobra. En ese momento esta asimetría se manifestará por un nistagmo parético, 
que constituye la primera fase del nistagmo de agitación cefálica [7, 14].

La prueba es patológica cuando el nistagmo dura más de 5 segundos. En ese caso se anotan la dirección y el sentido en el que bate, si revierte espontáneamente y cambia de sentido o si se modifica al inclinar la cabeza hacia un lado u otro [7].

Una exploración oculomotora normal en otoneurología presentaría en condiciones estáticas una ausencia de nistagmo espontáneo en las cinco posiciones de la mirada, excepto en mirada extrema, y la ausencia de nistagmo de rebote. Además, no deberíamos encontrar signos dinámicos, es decir, la maniobra de impulso óculo-cefálico no evidenciaría ninguna sacada de corrección y no aparecería nistagmo durante la vibración mastoidea, ni tras la prueba de agitación cefálica.

Hay que tener en cuenta que, en un paciente con una lesión periférica aguda, la alteración funcional completa del mecanismo de almacenamiento de velocidad determina que pueda no aparecer la primera fase del NAC, porque la aparición de un NAC implica la existencia de un almacenador de velocidad intacto. Igualmente, dado que este nistagmo está basado en una asimetría entre ambos lados, una pérdida bilateral y simétrica de la función vestibular tampoco mostrará NAC. En ocasiones, es posible encontrarlo en pacientes sin lesión vestibular evidente.

\section{DISCUSIÓN}

La valoración inicial de un paciente que acude a un servicio de urgencias por un síndrome vestibular agudo es fundamentalmente clínica y por lo tanto la exploración física es la que nos va a orientar en el diagnóstico inicial, muchas veces con una fiabilidad superior a las pruebas de imagen. Hay que tener en cuenta que entre un 4 y un $8,79 \%$ de los pacientes que acuden a urgencias con un síndrome vestibular agudo padecen un accidente cerebrovascular de la fosa posterior [15].

Sólo tras una cuidadosa exploración otoneurológica que busque diferentes signos de patología central, como se expresa en el protocolo HINTS, o dismetrías en las sacadas, seguimiento lento sacádico y alteraciones en la supresión/disminución del NE por fijación visual podremos empezar a descartar centralidad [16]. La exploración del NE con y sin fijación visual puede ser difícil de cuantificar si no realizamos una videonistagmografía. Sería una prueba poco sensible, pero con una especificidad mayor del $80 \%$ para patología central cuando no disminuye con fijación [17].

Por todo ello, el nistagmo espontáneo no puede ser el único pilar para decidir si un síndrome vertiginoso agudo es de origen periférico. Esto se debe a que están descritos cuadros clínicos que replican todas las características del NE de características periféricas, y aun así, tienen un origen central. Uno de estos cuadros sería el que se origina por un infarto en el territorio de la arteria cerebelosa ántero-inferior (AICA), que suele aparecer en pacientes con factores de riesgo cardiovascular y generalmente asociado a una hipoacusia neurosensorial súbita. Esta pérdida cocleovestibular puede preceder a un infarto de mayor extensión [18].

Por contra, la aparición de un nistagmo espontáneo de características centrales, por ejemplo, unidireccional en sentido vertical, debe hacernos pensar siempre en centralidad, incluso aunque la resonancia magnética sea normal a las 48 horas [19].

También aparece un nistagmo espontáneo en un $15,2 \%$ de los VPPB de conducto semicircular horizontal, que si se asocia a cupulolitiasis empeora la respuesta a las maniobras de reposición [20].

El nistagmo posagitación cefálica se considera una prueba con una baja sensibilidad (34$44 \%$ ) y una especificidad que varía mucho de unos estudios a otros, de entre un 65 a un $95 \%$ [21]. Se puede realizar de un modo pasivo, como la hemos descrito, o de un modo activo, donde el paciente es quien mueve su cabeza; los resultados coincidirían en un $74 \%$ de los pacientes [22]. Probablemente, el modo pasivo genera un estímulo más controlado.

En los déficits parciales vestibulares, el NAC es menos sensible que el test de vibración mastoidea y los resultados algo discordantes, mientras que en los déficits totales sus resultados concuerdan casi siempre. Esto se debe a que su origen fisiopatológico es diferente [23]. Están descritos casos de NAC en pacientes donde no aparece nistagmo durante la vibración mastoidea y viceversa.

Tiene la ventaja, como la vibración mastoidea, de que se puede aplicar a pacientes con perforaciones de la membrana timpánica en los que no es posible realizar pruebas calóricas. Su aparición se asocia a peores puntuaciones en la parte subjetiva del Dizziness Handicap Index [24]. 
Por tanto, el NAC tiene que ser interpretado con cautela, como un elemento más entre otros, en el diagnóstico de enfermedad vestibular. Su resultado negativo no indica que estemos ante un paciente sin alteraciones, pero su resultado positivo es un índice fiable de que hay o ha habido una disfunción vestibular.

\section{CONCLUSIONES}

El nistagmo espontáneo es el primer signo para valorar en un paciente con sensación de mareo o vértigo. La sencillez de su exploración y sus características son la herramienta fundamental para establecer nuestra sospecha diagnóstica, considerando por tanto la exploración vestíbulo-ocular, como el primer paso en el algoritmo diagnóstico del paciente inestable.

Un nistagmo horizontal y en resorte, que se intensifica bajo las gafas de Frenzel, apunta a un síndrome vestibular periférico agudo. Lo procesos vestibulares crónicos o los pacientes asintomáticos no tienen nistagmo espontáneo. Además, pocas personas pueden fingir un nistagmo espontáneo, que siempre será de corta duración.

EI NAC es una prueba clínica fácil de ejecutar, aunque no debería hacerse de forma aislada, sino junto a otras pruebas de exploración vestibular. Su baja sensibilidad e inconsistencia en señalar el lado afecto, especialmente en la enfermedad de Ménière, no debería desanimarnos a su realización, ya que puede señalar una vestibulopatía unilateral latente con alta especificidad [21].

La interpretación de la exploración oculomotora en otoneurología debe sustentarse en la cronología y evolución clínica del vértigo. Cualquier incongruencia de las características periféricas de un síndrome vertiginoso agudo nos obligaría a descartar un cuadro de etiología central.

\section{AGRADECIMIENTOS}

Agradecer al director de la revista y a los revisores del manuscrito, su tiempo y dedicación, haciendo este trabajo posible.

\section{BIBLIOGRAFÍA}

1. Bartual-Pastor J. Semiología vestibular. Unimed. 1st ed. Cádiz, 1980. ISBN: 84-3002862-5.
2. Brandt T, Dieterich M, Strupp M. Vertigo and Dizziness. [Ebook]. Springer-Verlag London Ltd, 2005. ISBN 978-1-84628-081-8

3. Bárány R. Untersuchungen über das Verhalten des Vestibularapparates bei Kopftraumen und ihre praktische Bedeutng. Verhandungen der Deutschen otol Gessellschaft 252-256, 1907.

4. Vogel K. Differentialdiagnostische Anhaltspunkte für die Erkennung von Schädigungen des Gleichgewichsapparates nach Schädelverletzungen. Deutsche Med Wochenschr 1929; 55(07): 268-70.

5. Hain TC, Spindler J. Head-shaking nystagmus. En: Sharpe JA, Barber HO, Eds: The vestibulo-ocular reflex and vertigo. New York: Raven Press.1993:217-28.

6. Kamei $\mathrm{T}$, Kimura $\mathrm{K}$, Kaneko $\mathrm{H}$, Noro $\mathrm{H}$. Reevaluation of the head shaking test as a method of nystagmus provocation. $\mathrm{J}$ OtoOtolaryngol (Japan). 1964;67:1530-4.

7. Bartual J, Pérez N: el sistema vestibular y sus alteraciones. Masson. Barcelona, 1999. Vol 1; pp. 88-90. ISBN 844580748X

8. Sanz-Fernández $R$, Martín-Sanz E. Exploración otoneurológica. Interpretación de las pruebas vestibulares. 1st Ed. Amplifon Ibérica. Barcelona, 2016. pp. 35-6. ISBN 97884-617-5421-2

9. Desmon AL. Vestibular function: evaluation and treatment. 1st Ed. Thieme. New York, 2004.

10. Santos Pérez $\mathrm{S}$, Pérez-Fernández N, Soto Varela A, Barona de Guzmán R. Síndrome vestibular periférico. R. Rev Med Univ Navarra 2003; 7(4):38-50.

11. Strupp $M$, Hüfner $K$, Sandmann $R$, Zwergal A, Dieterich $M$, Jahn $K$, et al. Central oculomotor disturbances and nystagmus: a window into the brainstem and cerebellum. Dtsch Arztebl Int. 2011;108(12):197-204..

12. Kattah J, Talkad A, Wang D, Hsieh $\mathrm{Y}$, Newman-Toker D. HINTS to Diagnose Stroke in the Acute Vestibular Syndrome. Stroke. 2009;40(11):3504-10.

13. Lalsa Shilpa $P$, Subjective Tests for Vestibular Dysfunction. Glob J Oto. 2017;5(3): 555664 . 
14. Zee DS. Afternystagmus and Headshaking nystagmus. Equilibrium Research. JSER;1993;52(3):442-7.

15. Batuecas-Caletrío A, Yánez-González R, Sánchez-Blanco C, González-Sánchez E, Benito J, Gómez JC, et al. Aplicación del protocolo HINTS. Rev Neurol. 2014;59:34953.

16. Brandt T, Strupp M, Dieterich M. Five keys for diagnosing most vertigo, dizziness, and imbalance syndromes: an expert opinion. $J$ Neurol. 2014;261(1):229-31.

17. An SY, Kim BJ, Suh MW, Rhee CK, Jung JY. Clinical roles of fixation suppression failure in dizzy patients in the ENT clinic. Acta Otolaryngol. 2014;134(11):1134-9.

18. Kim $\mathrm{H}$, Lee $\mathrm{H}$. Recent Advances in Understanding Audiovestibular Loss of a Vascular Cause. J Stroke. 2017;19(1):61-6.

19. Wegmann-Vicuña R, Muñoz-Hernández D, Gallegos-Constantino V, DomínguezEchavarri $P$, Irimia-Sieira $P$, PérezFernández N. Acute vestibular syndrome with down-beat nystagmus as a sole clinical presentation in AICA transient ischemic attack with an uncommon clinical course. Acta Otolaryngol Case Reports. 2017;2(1):131-36.

20. Son E, Lim H, Choung Y, Park K, Park H. Spontaneous nystagmus in horizontal canal benign paroxysmal positional vertigo. Auris Nasus Larynx. 2013;40(3):247-50.

21. Pérez Vázquez $P$, Rodríguez Prado $N$, Sequeiros Santiago G, Llorente Pendás JL, Gómez Martínez JR, Suárez Nieto C. Utilidad del nistagmo de agitación cefálica en la exploración vestibular clínica básica. Acta Otorrinolaringol Esp. 2005;56(7):300-4.

22. Gimeno-Vilar C, Rey-Martinez J, Perez N. Active versus passive head-shaking nystagmus. Acta Otolaryngol. 2007;127(7):722-8.
23. Dumas G, Lavieille J, Schmerber S. Caractérisation du test vibratoire. Comparaison avec les résultats du «Head shaking test ». Ann Otolaryngol Chir Cervicofac. 2004;121(1):22-32.

24. Angeli S, Velandia S, Snapp H. Headshaking nystagmus predicts greater disability in unilateral peripheral vestibulopathy. Am J Otolaryngol. 2011;32(6):522-7.

\section{ENLACES RELACIONADOS}

- Hain TC. Spontaneous Nystagmus. Dizziness-and- balance.com. 2013 Available from: https://www.dizziness-and-balance.com/practice/nystagmus/spontaneous.html [citado el 26 de octubre de 2017].

- Yacovino D. Nistagmus centrales (Central Type Nystagmus). Neurocienciasdelamemoriayelequilibrio.blogspot.com.es. 2017 Available from: http://neurocienciasdelamemoriayelequili-

brio.blogspot.com.es/p/portada.html [citado el 26 de octubre de 2017].

- Oliva-Domínguez, M. Anamnesis y exploración clínica (2016). [Internet]. Ponencia de la Sociedad Gallega de Otorrinolaringología 2016: "Rehabilitación Vestibular". Available from: https://www.researchgate.net/profile/Marcos_Rossi-Izquierdo/publication/309204106_Ponencia_de_la_Sociedad_Gallega_de_Otorrin olaringóogia_2016_Rehabilitacion_Vestibu-

lar/links/5805292508aef87fbf3bbc00/Ponencia-de-la-Sociedad-Gallega-deOtorrinolaringologia-2016-RehabilitacionVestibular.pdf [citado el 26 de octubre de 2017]. 